\title{
Correction to: Conflict-induced entrepreneurial resilience, self-efficacy and the new social compact: a study of BoP micro-entrepreneurs in conflict zones
}

\section{Ramendra Singh $(\mathbb{D} \cdot$ Tahir Wani • \\ Saiyed Wajid Ali Apoorv Khare}

Published online: 1 October 2021

(C) Indian Institute of Management Calcutta 2021

Correction to: Decision

https://doi.org/10.1007/s40622-021-00282-w

\section{Acknowledgements}

It has been incorrectly mentioned that, "The second author, Tahir Wani, has received research grant from ICSSR in India [ICSSR file no.02/75/2017-18/RP/ Major] for conducting this study."

The original article can be found online at https:// doi.org/10.1007/s40622-021-00282-w.

R. Singh $(\bowtie)$ K-303 New Academic Block, IIM Calcutta, D.H. Road, Joka, Kolkata, India

e-mail: ramendra@iimcal.ac.in

T. Wani

Department of Humanities and Social Sciences, National Institute of Technology Srinagar, Srinagar, India e-mail: tahirwani@nitsri.net

S. W. Ali

Centre for Management Studies, Jamia Millia Islamia, Jamia Nagar, Okhla, New Delhi 110025, India

e-mail: saiyed.wajid@gmail.com

\section{A. Khare}

IIM Tiruchirappalli, Tiruchirappalli, India

e-mail: apoorv@iimtrichy.ac.in
The correct statement should read as:

Acknowledgements The third author, Saiyed Wajid Ali has received research grant from ICSSR in India [ICSSR file no.02/ 75/2017-18/RP/Major] for conducting this study.

Publisher's Note Springer Nature remains neutral with regard to jurisdictional claims in published maps and institutional affiliations. 